
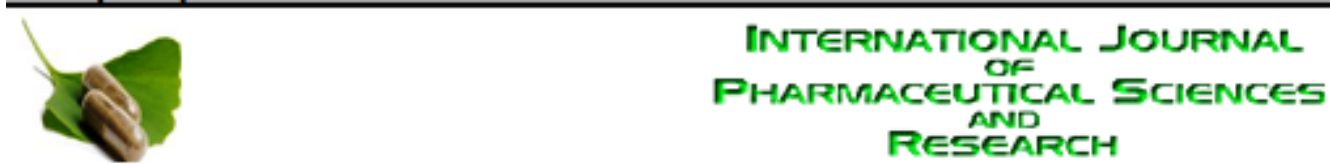

Received on 17 August, 2012; received in revised form 20 November, 2012; accepted 29 November, 2012

\title{
ANALYTICAL METHOD DEVELOPMENT OF ESOMEPRAZOLE IN BULK AND SINGLE COMPONENT FORMULATION
}

P.M. Rachmale

Modern College of Pharmacy, Yamunanagar, Nigdi, Pune, Maharashtra, India

\begin{tabular}{|c|c|}
\hline \multicolumn{2}{|c|}{$\begin{array}{l}\text { Esomeprazole, UV Analysis, Method } \\
\text { Development of Esomeprazole, Zero } \\
\text { Order UV- Analysis, First Order UV-Analysis }\end{array}$} \\
\hline \multicolumn{2}{|c|}{ Correspondence to Author: } \\
\hline \multicolumn{2}{|l|}{ P.M. Rachmale } \\
\hline \multicolumn{2}{|c|}{$\begin{array}{l}\text { Modern College of Pharmacy, } \\
\text { Yamunanagar, Nigdi, Pune, Maharashtra, } \\
\text { India }\end{array}$} \\
\hline \multicolumn{2}{|c|}{ E-mail: pundlikrachmale@ymail.com } \\
\hline QUICK RESPONSE CODE & \\
\hline \multirow{2}{*}{ 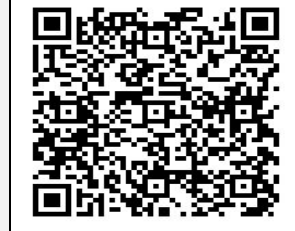 } & ICV (2011)- 5.07 \\
\hline & $\begin{array}{c}\text { Website: } \\
\text { www.ijpsr.com }\end{array}$ \\
\hline
\end{tabular}

ABSTRACT

Esomeprazole is a proton pump inhibitor which reduces gastric acid secretion through inhibition of $\mathrm{H}^{+} / \mathrm{K}^{+}$-ATPase in gastric parietal cells. By inhibiting the functioning of this enzyme, the drug prevents formation of gastric acid. Esomeprazole is combined with the antibiotics, clarithromycin and amoxicillin (or metronidazole in penicillin-hypersensitive patients) in the 7-14 day eradication triple therapy for Helicobacter pylori. Infection by $\mathrm{H}$. pylori is the causative factor in the majority of peptic and duodenal ulcers. Common side effects of Esomeprazole include headache, diarrhea, nausea, gas, decreased appetite, constipation, dry mouth, and abdominal pain. More severe side effects are severe allergic reactions, chest pain, dark urine, fast heartbeat, fever, paresthesia, persistent sore throat, severe stomach pain, unusual bruising or bleeding, unusual tiredness, and yellowing of the eyes or skin. Proton pump inhibitors may be associated with a greater risk of hip fractures and Clostridium difficile- associated diarrhea. Patients are frequently administered the drugs in intensive care as a protective measure against ulcers, but this use is also associated with a $30 \%$ increase in occurrence of pneumonia. It is not official in any of the Pharmacopoeias and only listed in The Merck Index and Martindale, The Complete Drug Reference. There is no official method reported for the estimation of Esomeprazole. Literature survey has indicated that there are no analytical methods for estimation of Esomeprazole single component by UV-Visible Spectrophotometry but there are few methods which are reported like RPHPLC method, validated Kinetic Spectrophotometric in commercial dosage forms, HPLC-UV method for the determination of Esomeprazole in human urine. Hence, the objective of the work is to develop simple, precise, accurate, sensitive, rapid and economical UV-Visible Spectrophotometric methods and a new simple HPLC method of analysis for the estimation of Esomeprazole in bulk and pharmaceutical formulations.

INTRODUCTION: All atoms and molecules are capable of absorbing energy in accordance with certain restrictions i.e. depending on the structure of the substance, energy may be furnished in the form of electromagnetic radiation. The kind and the amount of the radiation absorbed by a molecule depend on the number of molecules interacting with the radiation.
The study of these dependencies is called as "absorption spectroscopy". Quantitative spectroscopic analysis is based on the relationship between the amount of light absorbed and the amount of absorbing substance. The basic UV-Visible spectrophotometer is the absorption of the UV-Visible region, which arise $s$ from the electronic transition within the molecules by 
the radiant energy of definite and narrow wavelength of monochromatic radiation. Light absorption in the UV-Visible region causes the transition of an electron from a ground state and relaxation of energy takes place very rapidly. The important consequences of rapid relation of the excited states are not appreciably distributed by absorption of light energy from any source. Therefore, the fraction of light absorbed from an incident beam is independent of the intensity of these beams ${ }^{1}$.

Advantages of Instrumental Methods: Small amount of sample is needed for analysis, High sensitivity is obtained, Measurements obtained are reliable, The determination is very fast, Complex samples can be handled.

Limitations of Instrumental Methods: Skilled person is required, Cost of equipment is high, Sizable space is required, The sensitivity and accuracy depends on the instruments or wet chemical methods.

Techniques used in Instrumental Methods: There are many techniques available for the analysis of materials; however, they all are based on the materials interaction with energy. This interaction permits the creation of a signal that is subsequently detected and processed for its information content. Chemical instrumentation includes the following principle types 2 .

Spectroscopic techniques: Spectroscopy measures the interaction of the material with electromagnetic radiation. Different types are:

- Ultraviolet and visible spectrophotometry,

- Fluorescence and phosphorescence spectrophotometry,

- Atomic spectrometry (emission and absorption),

- Infrared spectrophotometry,

- Raman spectroscopy,

- X-ray spectroscopy,

- Nuclear magnetic resonance spectroscopy,

- Electron spin resonance spectroscopy.

Literature survey: Reported methods of analysis for Esomeprazole as a single component.
1. Development and statistical validation of spectroscopic method for estimation of Esomeprazole in tablet dosage form using UV visible spectrometer: Esomeprazole has the absorbance maxima at $303 \mathrm{~nm}$ (Method A), and in the first order derivative spectra, showed zero crossing at $303 \mathrm{~nm}$, with a sharp peak at $292 \mathrm{~nm}$ when $n=1$ (Method B), Method C applied was Area Under Curve (AUC) for analysis of Esomeprazole in the wavelength range of 294-310nm. Drug followed the Beer's Lamberts range of $5-40 \mu \mathrm{g} / \mathrm{ml}$ for the Method A, B C. Results of analysis were validated statistically ${ }^{3}$.

2. Physicochemical characterization U.V. spectrophotometric method development amd validation studies of Esomeprazole magnesium trihydrate:The method was based on U.V. absrption method. Method

a. Zero order spectrumMethod B) First order spectrumMethod C) AUC ${ }^{4}$.

3. Estimation of Esomeprazole and Domperidome by absorption ratio method in pharmaceutical dosage forms: The method involved $Q$-absorption analysis based on the measurement of absorbance at two wavelengths, i.e $\lambda$ max of Esomeprazole (303 nm) and Iso-absorptive point of both drugs $(290 \mathrm{~nm})^{5}$.

4. Development and validation of HPLC method for the determination of Esomeprazole:separation was achieved isocratically on a C18 column utilizing mobile phase of acetonitrile/phosphate buffer $(60: 40, v / v, \mathrm{pH} 7)$ Uvdetection at $205^{6}$.

5. Determination of Esomeprazole and its two metabolite in human, rat and dog plasma by liquid chomatography ${ }^{7}$.

\section{Nature of investigation:}

UV-Visible Spectrophotometer (Double Beam): Various modes in the mode selection screen of UvVisible Spectrophiotometer (Model UV 1700). 
Photometric Mode: This is the fixed wavelength measurement mode. This measures the absorbance (ABS) or \% transmittance (T \%) at a fixed wavelength.

Spectrum Mode: This is the mode in which spectral measurement is performed. There are three types of measurement available i.e. ABS (absorbance), T \% (\% transmittance) and single beam E (energy) ${ }^{6}$.

Quantitation Mode: This is the mode in which unknown concentration of samples are measured by plotting a calibration curve of standard solutions. The following 4 methods in quantitation mode are available, which depend on the number of wavelengths used for the measurement:

1. One - wavelength method

2. Two-wavelength method

3. Three - wavelength method

4. Derivative quantitation ${ }^{7}$

TABLE 1:

\begin{tabular}{cc}
\hline Make & $\begin{array}{c}\text { Shimadzu Corporation Ltd., } \\
\text { Japan }\end{array}$ \\
\hline Model & UV 1700 \\
\hline Specification & 190 to $1100 \mathrm{~nm}$ \\
\hline $\begin{array}{c}\text { Wavelength range Spectral } \\
\text { Bandwidth }\end{array}$ & $2 \mathrm{~nm}$ \\
\hline
\end{tabular}

Goals of investigation: Esomeprazole is a proton pump inhibitor which reduces gastric acid secretion through inhibition of $\mathrm{H}^{+} / \mathrm{K}^{+}$-ATPase in gastric parietal cells. By inhibiting the functioning of this enzyme, the drug prevents formation of gastric acid. Esomeprazole is combined with the antibioticsclarithromycin and amoxicillin (or metronidazole in penicillin-hypersensitive patients) in the 7-14 day eradication triple therapy for Helicobacter pylori. Infection by H. pylori is the causative factor in the majority of peptic and duodenal ulcers.

Common side effects of Esomeprazole include headache, diarrhea, nausea, gas, decreased appetite, constipation, dry mouth, and abdominal pain. More severe side effects are severe allergic reactions, chest pain, dark urine, fast heartbeat, fever, paresthesia, persistent sore throat, severe stomach pain, unusual bruising or bleeding, unusual tiredness, and yellowing of the eyes or skin.
Proton pump inhibitors may be associated with a greater risk of hip fractures and clostridium difficileassociated diarrhea. Patients are frequently administered the drugs in intensive care as a protective measure against ulcers, but this use is also associated with a $30 \%$ increase in occurrence of pneumonia. It is not official in any of the Pharmacopoeias and only listed in The Merck Index, and Martindale, The Complete Drug Reference.

There is no official method reported for the estimation of Esomeprazole. Literature survey has indicated that there are no analytical methods for estimation of Esomeprazole single component by UV-Visible Spectrophotometry but there are few methods which are reported like RP-HPLC method, validated Kinetic Spectrophotometric in commercial dosage forms, HPLC-UV method for the determination of Esomeprazole in human urine. Hence the objective of the work is to develop simple, precise, accurate, sensitive, rapid and economical UV-Visible Spectrophotometric methods and a new simple HPLC method of analysis for the estimation of Esomeprazole in bulk and pharmaceutical formulations.

\section{Drug Profile:}

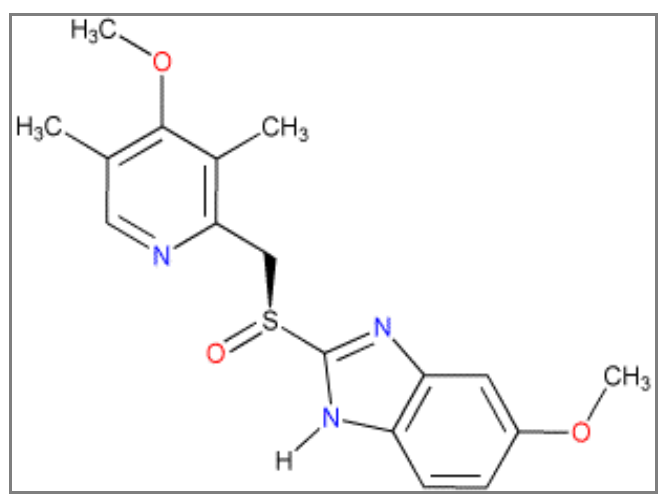

TABLE $2^{12}$ :

\begin{tabular}{|c|c|}
\hline Mol. Formula & $\mathrm{C}_{17} \mathrm{H}_{19} \mathrm{~N}_{3} \mathrm{O}_{3} \mathrm{~S}$ \\
\hline Mol. Weight & $345.417 \mathrm{~g} / \mathrm{mol}$ \\
\hline & (S)-5-methoxy-2-[(4-methoxy-3,5- \\
\hline Chemical Name & $\begin{array}{l}\text { dimethylpyridin-2-yl)methylsulfinyl]-3H- } \\
\text { benzoimidazole }\end{array}$ \\
\hline Description & white to slightly colored crystalline powder \\
\hline Solubility & Very slightly soluble in water \\
\hline Melting Point & $155^{\circ} \mathrm{C}$ \\
\hline \multirow{4}{*}{ Category } & Anti-Ulcer Agents \\
\hline & Enzyme Inhibitors \\
\hline & Proton-pump Inhibitors \\
\hline & Antihistamines \\
\hline
\end{tabular}




\section{MATERIALS AND METHODS:}

Plan of work: Selection of single component formulation, Market surveys, Solvent selection, Selection of analytical wavelength, Type of instrument, Preparation of working curve, Sample measurement and calculations, Evaluation of reproducibility and recognitions of variations ${ }^{13,14}$.

Method's:

- Zero order spectrum method.

- Derivative spectrum method.

Validation of analytical method's ${ }^{15}$ :

1. Analytical Procedure

2. Specificity

3. Sensitivity

4. Accuracy

5. Precision

6. Robustness

7. Limit of detection

8. Linearity

9. Stability

10.Limit of quantitation

11.Range

12. Cost of analysis

Year of experimentation: 2012-13.

Site: Modern college of Pharmacy, Nigdi, Pune.

\section{RESULTS AND DISCUSSION:}

\section{Zero Order Spectrum (Calibration Curve Method):}

A. Preparations of drug stock solution: Accurately about $10 \mathrm{mg}$ of ESOMEPRAZOLE was weighed and transferred to $100 \mathrm{ml}$ volumetric flask. To it $40 \mathrm{ml}$ of ethanol was added to dissolve the drug completely with vigorous shaking then the volume was made up with distilled water up to the mark to give the drug stock solution of concentration $100 \mu / \mathrm{ml}$.

B. Preparation of Standard Drug Dilutions: From the stock solution of ESOMEPRAZOLE appropriate volumes were pipetted out and transferred to 10 $\mathrm{ml}$ volumetric flasks. The volume was made up to the mark with glass distilled water to give the samples of desired concentrations.

Selection of analytical wavelengths: The standard solutions were then scanned in the spectrum mode of the instrument from $400 \mathrm{~nm}$ to $200 \mathrm{~nm}$ against glass distilled water as blank. The zero order derivative spectrum obtained with wavelength difference $(n=0)$ showed a sharp peak was obtained at $301 \mathrm{~nm}$ as shown in figure 1.

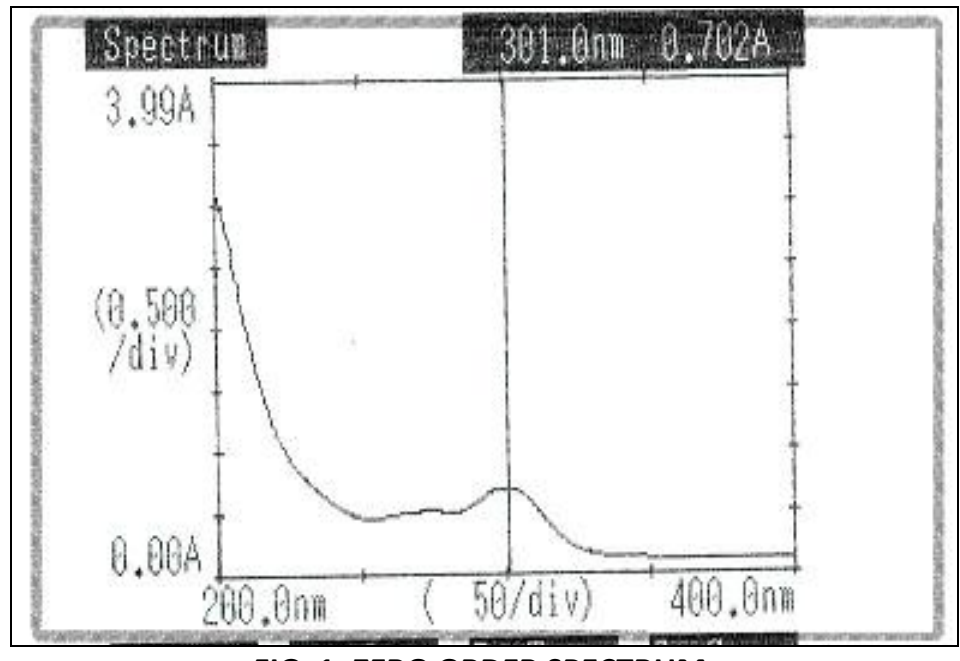

FIG. 1: ZERO ORDER SPECTRUM

TABLE 2: STANDARD CALIBRATION TABLE FOR ESOMEPRAZOLE

\begin{tabular}{ccc}
\hline Sr. No. & Conc. $\boldsymbol{\mu g} / \mathbf{m l}$ & Absorbance \\
\hline $\mathbf{1}$ & 20 & 0.210 \\
$\mathbf{2}$ & 30 & 0.315 \\
$\mathbf{3}$ & 40 & 0.420 \\
$\mathbf{4}$ & 50 & 0.510 \\
$\mathbf{5}$ & 60 & 0.620 \\
$\mathbf{6}$ & 70 & 0.700 \\
$\mathbf{7}$ & 80 & 0.820 \\
$\mathbf{8}$ & 20 & 0.210 \\
\hline
\end{tabular}

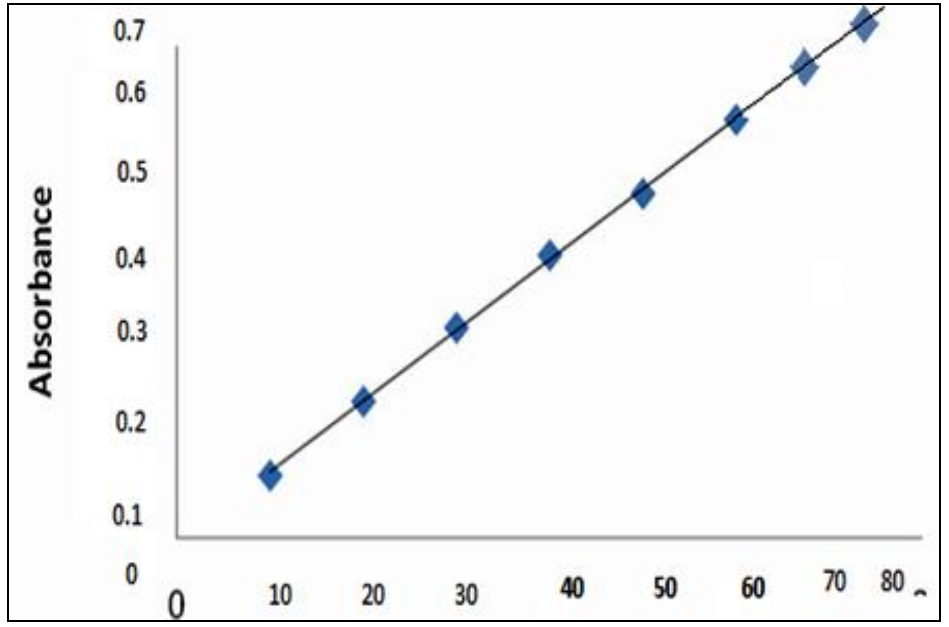

FIG. 2: CALIBRATION CURVE ESOMEPRAZOLE IN ZERO ORDER DERIVATIVE SPECTRUM 
TABLE 3: OPTICAL CHARACTERISTICS AND PARAMETERS

\begin{tabular}{cc}
\hline Parameters & Method A \\
\hline$\lambda_{\max }(\mathbf{n m}) /$ wavelength range $(\mathbf{n m})$ & 301 \\
Beer's-Lamberts range $(\mu \mathrm{g} / \mathbf{m l})$ & $20-80$ \\
Coefficient of Correlation $\left(\mathbf{r}^{2)}\right.$ & 0.9990 \\
Regression Equation $\mathbf{y}=\mathbf{m x + c}$ & \\
Slope $(\mathrm{m})$ & 0.0107 \\
Intercept $(\mathrm{c})$ & 0.0000 \\
LOD & 0.1296 \\
LOQ & 0.3928 \\
\hline
\end{tabular}

TABLE 4: STATISTICAL VALIDATION BY ZERO ORDER SPECTRUM METHOD

\begin{tabular}{ccccc}
\hline Parameter & Mean & S.D* & C.O.V. ${ }^{*}$ & S.E. $^{*}$ \\
\hline $\mathbf{r}^{2}$ & 0.9990 & 0.0004203 & 0.042072 & 0.00017159 \\
Slope & 0.0107 & 0.00088374 & 0.088370 & 0.00036078 \\
Intercept & 0.0000 & 0.0000 & 0.0000 & 0.0000 \\
\hline
\end{tabular}

TABLE 4[A]: ANALYSIS OF STANDARD ESOMEPRAZOLE

\begin{tabular}{cccc}
\hline Conc. Taken & ABS. At $\mathbf{3 0 1} \mathbf{~ n m}$ & Conc. Obtained & \% of Drug Found * \\
\hline 20 & 0.210 & 8.30 & 83 \\
30 & 0.315 & 30.5 & 95.5 \\
40 & 0.420 & 38.7 & 96.75 \\
50 & 0.510 & 46.8 & 93.6 \\
60 & 0.620 & 60.1 & 100.1 \\
70 & 0.700 & 69.3 & 99 \\
80 & 0.820 & 79.2 & 99 \\
\hline
\end{tabular}

TABLE 4B: ASSAY OF THE TABLE

\begin{tabular}{ccccc}
\hline Tablet & Conc. & Amount present (mg/Tab) & Amount found (mg /Tab) & \% of Drug Found \\
\hline & 40 & 10 & 39.40 & 98.5 \\
$T_{1}$ & 70 & 10 & 68.10 & 97.28 \\
& 80 & 10 & 80.20 & 100.25 \\
\hline
\end{tabular}

The results of the analysis of tablet formulations by Zero order spectrum method are given below in Table 5 .

TABLE 5[A]: ANALYSIS OF TABLET FORMULATION

\begin{tabular}{cccc}
\hline Tablet sample & Amount present $(\mathbf{m g} / \mathbf{t a b})$ & Amount Found $\mathbf{( m g / t a b )}$ & \% of Label Claim \\
\hline & 40 & 39.45 & 98.57 \\
& 40 & 40.01 & 100.25 \\
$\mathrm{~T}_{1}$ & 40 & 38.98 & 97.45 \\
& 40 & 39.10 & 97.75 \\
& 40 & 40.10 & 100.25 \\
& 40 & 39.00 & 97.5 \\
\hline
\end{tabular}

TABLE 5[B]:STATISTICAL EVALUTION BY ZERO ORDER SPECTRUM METHOD

\begin{tabular}{ccccc}
\hline Tablet sample & \% Mean & S.D & C.O.V & S.E \\
\hline $\mathrm{T}_{1}$ & 98.60 & 1.110 & 1.125 & 0.453 \\
\hline
\end{tabular}

Recovery Studies: The result of analysis of recovery studies and its statistical validation are given in table 6 and 7 respectively. 
TABLE 6: RECOVERY STUDIES

\begin{tabular}{ccccc}
\hline $\begin{array}{c}\text { Tablet } \\
\text { Sample }\end{array}$ & $\begin{array}{c}\text { Level of } \\
\text { Recovery (\%) }\end{array}$ & $\begin{array}{c}\text { Amount present } \\
(\mathbf{m g} / \mathbf{t a b})\end{array}$ & $\begin{array}{c}\text { Amount Standard } \\
(\mathbf{m g})\end{array}$ & $\begin{array}{c}\text { Total Amount Recovered } \\
(\mathbf{m g})\end{array}$ \\
\hline & \multirow{3}{*}{80} & 10 & 8 & 18.20 \\
\% Recovery
\end{tabular}

TABLE 7 : STATISTICAL VALIDATION OF RECOVERY STUDIES

\begin{tabular}{cccccc}
\hline Tablet sample & Level of recovery (\%) & \% Mean* & S.D.* & C.O.V.* & S.E.* \\
\hline \multirow{2}{*}{$\mathrm{T}_{1}$} & 80 & 100.35 & 0.02764 & 0.02754 & 0.01595 \\
& 100 & 100.10 & 1.625 & 1.623 & 0.9370 \\
& 120 & 99.54 & 0.7208 & 0.7241 & 0.4180 \\
\hline
\end{tabular}

When $* n=3$ at each level of recovery

TABLE 8: STATISTICAL VALIDATION FOR PRECISION

\begin{tabular}{ccccc}
\hline Component & Mean $*$ & S.D. & C.O.V. & S.E. \\
\hline Intra-day & 99.77 & 0.0100 & 0.01002 & 0.005774 \\
Inter-day & 99.50 & 0.005774 & 0.005803 & 0.003333 \\
\hline
\end{tabular}

First Order Derivative Method:

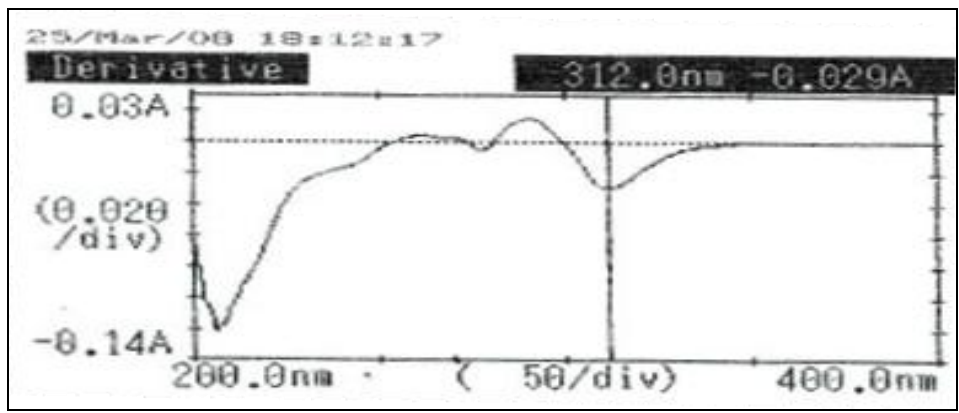

TABLE 9: STANDARD CALIBRATION TABLE FOR ESOMEPRAZOLE

\begin{tabular}{ccc}
\hline Sr. No. & Conc. $\boldsymbol{\mu g} / \mathbf{m l}$ & Absorbance \\
\hline $\mathbf{1}$ & 10 & -0.005 \\
$\mathbf{2}$ & 20 & -0.010 \\
$\mathbf{3}$ & 30 & -0.015 \\
$\mathbf{4}$ & 40 & -0.020 \\
$\mathbf{5}$ & 50 & -0.025 \\
$\mathbf{6}$ & 60 & -0.030 \\
$\mathbf{7}$ & 70 & -0.035 \\
$\mathbf{8}$ & 80 & -0.040 \\
\hline
\end{tabular}

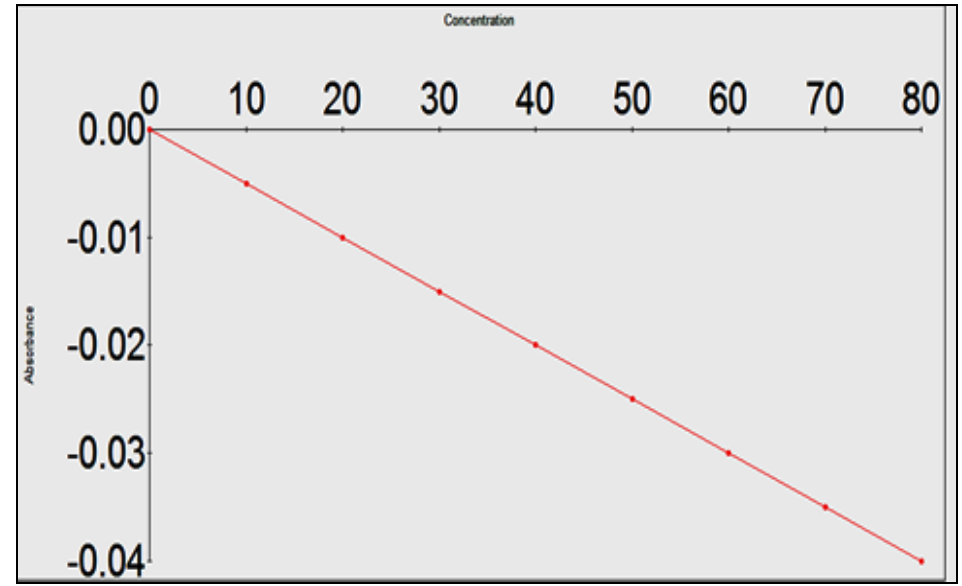

CALIBRATION CURVE OF ESOMEPRAZOLE INFIRST ORDER DERIVATIVE SPECTRUM

TABLE 10: OPTICAL CHARACTERISTICS AND OTHER PARAMETERS

\begin{tabular}{cc}
\hline Parameters & Method A \\
\hline $\boldsymbol{\lambda}_{\max }(\mathrm{nm}) /$ wavelength range $(\mathrm{nm})$ & 312 \\
Beer's-Lamberts range $(\boldsymbol{\mu g} / \mathrm{ml})$ & $10-80$ \\
Coefficient of Correlation $\left(\mathrm{r}^{2)}\right.$ & 0.9991 \\
Regression Equation $\mathbf{y}=\mathbf{m x + c}$ & \\
Slope $(\mathrm{m})$ & -0.0119 \\
Intercept $(\mathrm{c})$ & 0.0000 \\
LOD & -0.507 \\
LOQ & -1.539 \\
\hline
\end{tabular}

TABLE 11: STATISTICAL VALIDATION BY ZERO ORDER SPECTRUM METHOD

\begin{tabular}{ccccc}
\hline Parameter & Mean & S.D* & C.O.V.* & S.E.* $^{*}$ \\
\hline $\mathbf{r}^{2}$ & 0.9991 & 0.0018316 & 0.0018330 & 0.0007477 \\
Slope & -0.0119 & 0.002328 & 0.2326 & 0.0009504 \\
Intercept & 0.000 & 0.0000 & 0.0000 & 0.0000 \\
\hline
\end{tabular}

*Average of six readings 
TABLE 12: ASSAY OF THE TABLE

\begin{tabular}{ccccc}
\hline Tablet & Conc. & Amount present $(\mathbf{m g} / \mathrm{Tab})$ & Amount found (mg /Tab) & \% of Drug Found \\
\hline & 40 & 10 & 40.12 & 100.3 \\
$\mathbf{T}_{1}$ & 70 & 10 & 69.89 & 99.84 \\
& 80 & 10 & 80.40 & 100.5 \\
\hline
\end{tabular}

TABLE 13 : ANALYSIS OF STANDARD ESOMEPRAZOLE

\begin{tabular}{cccc}
\hline Conc. Taken & ABS. at 312 $\mathbf{~ n m}$ & Conc. Obtained & \% of Drug Found * \\
\hline 10 & -0.005 & 9.76 & 97.6 \\
20 & -0.010 & 19.20 & 96 \\
30 & -0.015 & 28.90 & 96.6 \\
40 & -0.020 & 39.78 & 99.45 \\
50 & -0.025 & 49.45 & 98.5 \\
60 & -0.030 & 59.90 & 99.83 \\
70 & -0.035 & 68.20 & 97.42 \\
80 & -0.040 & 79.10 & 100.12 \\
\hline
\end{tabular}

*Average of six readings

TABLE 14: ANALYSIS OF TABLET FORMULATIONS

\begin{tabular}{cccc}
\hline Tablet sample & Amount Present (mg/tab) & Amount Found (mg/tab) & \% of Label Claim \\
\hline & 10 & 9.12 & 97.8 \\
& 10 & 9.80 & 99.5 \\
T $_{1}$ & 10 & 8.99 & 97.47 \\
& 10 & 10.02 & 100.05 \\
& 10 & 10.07 & 100.17 \\
& 10 & 9.99 & 99.97 \\
\hline
\end{tabular}

$\mathrm{T}_{1}$ : is the brands of tablet formulations.

TABLE 15: STATISTICAL EVALUATION BY FIRST ORDER DERIVATIVE SPECTRUM METHOD

*Average of six readings

\begin{tabular}{ccccc}
\hline Table Sample & \% Mean* & S.D. ${ }^{*}$ & C.O.V. ${ }^{*}$ & S.E. $^{*}$ \\
\hline $\mathrm{T}_{1}$ & 98.16 & 0.9622 & 0.9704 & 0.3928 \\
\hline
\end{tabular}

\section{TABLE 16:RECOVERY STUDIES}

\begin{tabular}{|c|c|c|c|c|c|}
\hline $\begin{array}{l}\text { Tablet } \\
\text { Sample }\end{array}$ & $\begin{array}{c}\text { Level of Recovery } \\
\text { (\%) }\end{array}$ & $\begin{array}{c}\text { Amount present } \\
\text { (mg/tab) }\end{array}$ & $\begin{array}{l}\text { Amount Standard } \\
\text { (mg) }\end{array}$ & $\begin{array}{c}\text { Total Amount Recovered } \\
\text { (mg) }\end{array}$ & \% Recovery \\
\hline \multirow{9}{*}{$\mathbf{T}_{1}$} & \multirow{3}{*}{80} & 10 & 8 & 18.08 & 100.44 \\
\hline & & 10 & 8 & 17.99 & 99.94 \\
\hline & & 10 & 8 & 18.02 & 100.11 \\
\hline & \multirow{3}{*}{100} & 10 & 10 & 20.10 & 100.5 \\
\hline & & 10 & 10 & 20.03 & 100.15 \\
\hline & & 01 & 10 & 19.99 & 99.95 \\
\hline & \multirow{3}{*}{120} & 10 & 12 & 22.04 & 100.18 \\
\hline & & 10 & 12 & 21.86 & 99.36 \\
\hline & & 10 & 12 & 21.96 & 99.81 \\
\hline
\end{tabular}

TABLE 17: STATISTICAL VALIDATION OF RECOVERY STUDIES

\begin{tabular}{cccccc}
\hline Table Sample & Level of Recovery (\%) & \% Mean* & S.D. ${ }^{*}$ & C.O.V.* $^{*}$ & S.E. $^{*}$ \\
\hline & 80 & 100.16 & 0.2076 & 0.2072 & 0.1198 \\
$\mathrm{~T}_{1}$ & 100 & 100.02 & 0.2273 & 0.2268 & 0.1312 \\
& 120 & 99.78 & 0.3353 & 0.3360 & 0.1935 \\
\hline
\end{tabular}

When ${ }^{*} n=3$ at each level of recovery

TABLE 17A: STATISTICAL VALIDATION DATA FOR ESOMEPRAZOLE

\begin{tabular}{ccccc} 
Method & \% Mean * & S.D. & C.O.V. & S.E. \\
\hline Method A & 98.7 & 1.110 & 98.6 & 98.7 \\
Method B & 99.16 & 0.9622 & 99.98 & 99.16 \\
\hline
\end{tabular}

TABLE 18: STATISTICAL VALIDATION FOR PRECISION

\begin{tabular}{ccccc}
\hline Component & Mean $*$ & S.D. & C.O.V. & S.E. \\
\hline Intra-day & 99.55 & 0.007528 & 0.007562 & 0.003073 \\
Inter-day & 99.75 & 0.004082 & 0.004092 & 0.001667 \\
\hline
\end{tabular}


TABLE 19: OPTICAL CALIBRATION CURVE OF ESOMEPRAZOLE

\begin{tabular}{ccc}
\hline Parameters & Method A & Method B \\
\hline max $(\mathbf{n m}) /$ wavelength range $(\mathbf{n m})$ & 301 & 312 \\
Beer's - Lambert's range $(\mu \mathrm{g} / \mathbf{m l})$ & $20-80$ & $10-80$ \\
Coefficient of correlation $\left(\mathbf{r}^{2}\right)$ & 0.9990 & 0.9996 \\
Regression equation : $\mathbf{Y}=\mathbf{m x}+\mathbf{c}$ & & \\
Slope $(\mathrm{m})$ & 0.1296 & -0.00198 \\
Intercept $(\mathrm{c})$ & 0.0000 & 0.0000 \\
LOD & 0.0107 & -0.507 \\
LOQ & 0.1226 & -1.539 \\
\hline
\end{tabular}

CONCLUSION: It is not official in any of the Pharmacopoeias and only listed in The Merck Index, and Martindale, The Complete Drug Reference. There is no official method reported for the estimation of Esomeprazole. Literature survey has indicated that there are no analytical methods for estimation of Esomeprazole single component by UV-Visible Spectrophotometry but there are few methods which are reported like RP-HPLC method, validated Kinetic Spectrophotometric in commercial dosage forms, HPLC-UV method for the determination of Esomeprazole in human urine.

Hence, the objective of the work is to develop simple, precise, accurate, sensitive, rapid and economical UVVisible Spectrophotometric methods and a new simple HPLC method of analysis for the estimation of Esomeprazole in bulk and pharmaceutical formulations.

The methods were based on the development of calibration curve for the standard drug and the analysis of the formulation aws done using the calibration curve in the quantitation mode of the Spectrophotometer (Method A). The standard drug solution were scanned in the spectrum mode and the first order derivative spectra with $(n=1)$ processed showed zero crossing at the absorbance maxima of the normal spectra, the derivative $\mathrm{dA} / \mathrm{d} \lambda$ is plotted against the concentration of the standard solution (Method B).

\section{REFERENCES:}

1. Christian G. D., In: Analytical Chemistry 6th Edn, Wiley international, 2004, 60 .

2. Robert E., Notari, In; Biopharmaceutical and Chemical Pharmacokinetics, 4th Edn, A Textbook for Pharmacy Students and Pharmaceutical Chemists, 1987, 2.

3. Watson G. D., Pharmaceutical Analysis, Elsevier Churchill Livingstone, 2nd Edn, A Textbook of Pharmacy, Student and Pharmaceutical Chemistry 2005, 5.

4. Mendham J., Denny R. C. and Thomas ML, In; Vogel's Text Book of Quantitative Analysis, 6th Edn, Pearson Education Limited, 2004, 1-10, 268.

5. Skoog D. A., Holler F.J. and Nieman T. A., In: Principle of Instrumental Analysis, 3rd Edn., Saunders College Publications, London, 1985, 1.

6. Davidson A G., In: Practical Pharmaceutical Chemistry, 4th Edn, Vol. 2, CBS Publishers and Distributors, New Delhi, 1997, 275.

7. Connors K. A., In: A Textbook of Pharmaceutical Analysis, 3rd Edn, Wiley Interscience Publications, 1999, pg 408.

8. Kalsi P. S., In: Spectroscopy of organic compound, 5th Edn., New age International Publisher's, New Delhi, 7.

9. Sharma Y. R., In: Introduction of Organic Spectroscopy, 4th Edn, CBS Publishers and Distributors, New Delhi, 1991, 22.

10. Swarbric J. and Boylan J. C, In: Encyclopedia of Pharmaceutical Technology, Vol. 15, Marcel Dekker Inc., New York, 1997, 297.

11. Beckett A. H., and Stenlake J. B., In: Practical Pharmaceutical Chemistry, 4th Edn, Part 2, CBS Publishers and Distributors, 2002, 290.

12. Kasture A. V., Mahadik K. R.; Wadodkar S. G., and More H. N., In: Pharmaceutical Analysis, Vol.11, Nirali Prakashan, 48-57, 156

13. Schirmer R. E., In: Modern Methods of Pharmaceutical Analysis, 2nd Edn. Vol.1, CRC Press, 1991, pg 31

14. ICH, Q2A, Text on Validation of Analytical Procedures, International Conference on Harmonization, Geneva, October 1994, 1.

15. ICH, Q2B, Validation of Analytical Procedures: Methodology, International conference on ha Harmonization, Geneva, November, 1996, 1.

How to cite this article:

Rachmale PM: Analytical Method Development of Esomeprazole in Bulk and Single Component Formulation. Int J Pharm Sci Res. $3(12) ; 5067-5074$. 